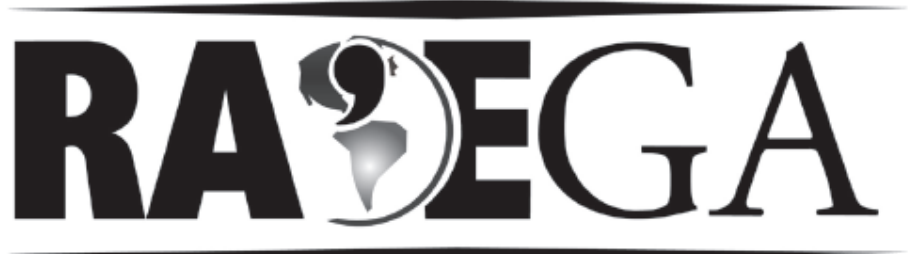

O ESPAÇO GEOGRÁFICO EM ANÁLISE

\title{
MODELAGEM DA PRODUÇÃO DE SEDIMENTOS NA SUB-BACIA HIDROGRÁFICA DO RIACHO JACARÉ - SE
}

\section{MODELING SEDIMENT PRODUCTION TO PLAN LAND USE IN THE SUB-BASIN OF JACARE RIVER - SE}

\author{
Fabrício Lopes de Macedo ${ }^{1}$ \\ Arisvaldo Vieira Méllo Júnior ${ }^{2}$ \\ Silvana Susko Marcellini ${ }^{3}$ \\ Alceu Pedrotti ${ }^{4}$
}

\section{RESUMO}

A produção de sedimentos nas bacias hidrográficas constitui um aspecto importante para o planejamento do uso e ocupação do solo. Modelos matemáticos são ferramentas úteis para a análise do problema fornecendo rapidez, praticidade e flexibilidade as simulações de condições atuais e futuras. Neste artigo foi avaliada uma metodologia para simular a produção de sedimentos em distintos cenários de uso e ocupação do solo utilizando de forma combinada a MUSLE, o modelo hidrológico ABC e um SIG. A modelagem utilizada apresentou bom desempenho para fins de planejamento do uso e ocupação do solo, bem como para o planejamento agrícola e ambiental.

Palavras-chave: produção de sedimento; uso do solo; MUSLE.

\footnotetext{
1 Engenheiro Agrônomo, Mestre em Agroecossistemas, Doutorando em Agronomia. Universidade Estadual Paulista, Faculdade de Engenharia, Departamento de Fitossanidade, Engenharia Rural e Solos, Ilha Solteira, São Paulo. Email - fabriciolmacedo@hotmail.com

2 Engenheiro Agrônomo, Mestre em Agronomia, Doutor em Engenharia Civil. Escola Politécnica, Universidade de São Paulo. Email - arisvado@usp.br

3 Engenheira Civil, Mestre em Engenharia Civil, Doutora em Engenharia Civil. Escola Politécnica, Universidade de São Paulo. Email - susko@uol.com.br

${ }^{4}$ Engenheiro Agrônomo, Mestre em Agronomia, Doutor em Ciência do Solo. Departamento de Engenharia Agronômica, Universidade Federal de Sergipe. São Cristóvão, Sergipe. Email - apedrotti@ufs.br
} 


\section{ABSTRACT}

The sediment production in river basins is an important aspect for planning the land use. Mathematical models are useful tools for analyzing the problem by providing speed, convenience and flexibility to the simulations of current conditions and future. In this article we evaluate a methodology to simulate the sediment production combining the MUSLE, a hydrologic model (ABC) and a GIS in different scenarios of land use. The models used showed good performance for purposes of planning land use, as well as for agricultural and environmental planning.

Keywords: sediment production; land use; MUSLE.

\section{Introdução}

Numa bacia hidrográfica, o uso e ocupação do solo determinam o escoamento da água e a produção de sedimentos. A falta de planejamento no uso dos recursos naturais e decisões equivocadas no manejo do solo podem provocar podem causar danos ao meio ambiente. A erosão do solo tem sido a principal causa de degradação ambiental causando perdas de solo agricultável (SILVA et al., 2005 a, b; PANACHUKI et al., 2006; CARVALHO, 2008; CARVALHO et al., 2009), assoreamento e contaminação dos cursos d'água, lagos e represas (VESTENA, 2009).

A erosão hídrica do solo resulta da ocorrência simultânea de vários fatores associados aos efeitos da erosividade das precipitações e à erodibilidade do solo em que os principais fatores estão relacionados ao uso do solo (topografia, cobertura vegetal, práticas de conservação e manejo) e às suas características físicas (WISCHMEIER \& SMITH, 1978). A complexa interação entre estes fatores tornam difíceis a análise do processo erosivo e a quantificação da produção de sedimento na bacia. Segundo Machado et al. (2003), modelos matemáticos possibilitam analisar grandes quantidades de dados, relacionados aos diferentes cenários, de modo a auxiliar numa melhor compreensão sobre os processos que ocorrem no sistema, de forma econômica, rápida e prática. Sistemas de Informações Geográficas (SIG) constituem uma categoria de modelos utilizados para visualizar e manipular dados espacialmente facilitando a análise das condições de manejo ocorridas no passado bem como para simular condições futuras (FARINASSO et al., 2006; MACHADO et al., 2009). 
Esses instrumentos são úteis para auxiliar o planejamento do uso dos recursos hídricos e do uso do solo nas bacias.

Neste artigo será apresentada uma metodologia para simular a produção de sedimentos em cenários distintos de uso e ocupação do solo utilizando de forma combinada a equação da perda de solo modificada, um modelo hidrológico e um SIG. Foi analisada a influência de matas secundárias, em dois cenários distintos de uso e ocupação do solo, para a minimização da produção de sedimento e controle do processo erosivo na sub-bacia do Rio Jacaré, no Estado de Sergipe.

\section{Materiais e Métodos}

\section{Caracterização da bacia}

A sub-bacia hidrográfica do Riacho Jacaré está localizada ao norte do Estado de Sergipe sendo um afluente da margem direita do Rio São Francisco, ocupa uma área aproximada de $324,81 \mathrm{~km}^{2}$, possui uma extensão de $44 \mathrm{~km}^{2}$, sua nascente é próximo ao povoado de Lagoa Seca perto da cidade de Aquidabã, a uma altitude de $220 \mathrm{~m}$.

O sentido do escoamento do riacho é nordeste de sua nascente até a confluência com o Rio São Francisco. As declividades são mais acentuadas (12 $\mathrm{m} \mathrm{km}^{-1}$ ) ocorrem no trecho inicial. Os principias afluentes são os Riachos Buri, que está localizado na margem direita do Riacho Jacaré e é perene, e Campo Grande, afluente da margem esquerda que possui minadouros perenes com a formação de poços (AGUIAR NETTO et al., 2008).

De acordo com a classificação de Koppen, o clima da sub-bacia é SemiÁrido (BShi), ou seja, com estação seca no verão, com evapotranspiração potencial média anual superior à precipitação média anual, temperaturas sempre superiores aos $18^{\circ} \mathrm{C}$ e amplitude térmica mensal menor que $5^{\circ} \mathrm{C}$. A precipitação da sub-bacia possui uma distribuição média anual que varia de 900 a 1100 mm (SERGIPE, 2004).

As classes de solo predominantes na sub-bacia são os Neossolos que ocorrem nas variações com os Neossolos Litólicos, os Neossolos Regolíticos e 
os Neossolos Flúvicos. Estes ocorrem na parte baixa da bacia e ocupa uma área de aproximadamente dois terços da área total da sub-bacia. Na parte alta da sub-bacia estão presentes as classes de solos Argissolo Vermelho Amarelo e Argissolo Vermelho Amarelo Eutrófico (SERGIPE, 2004).

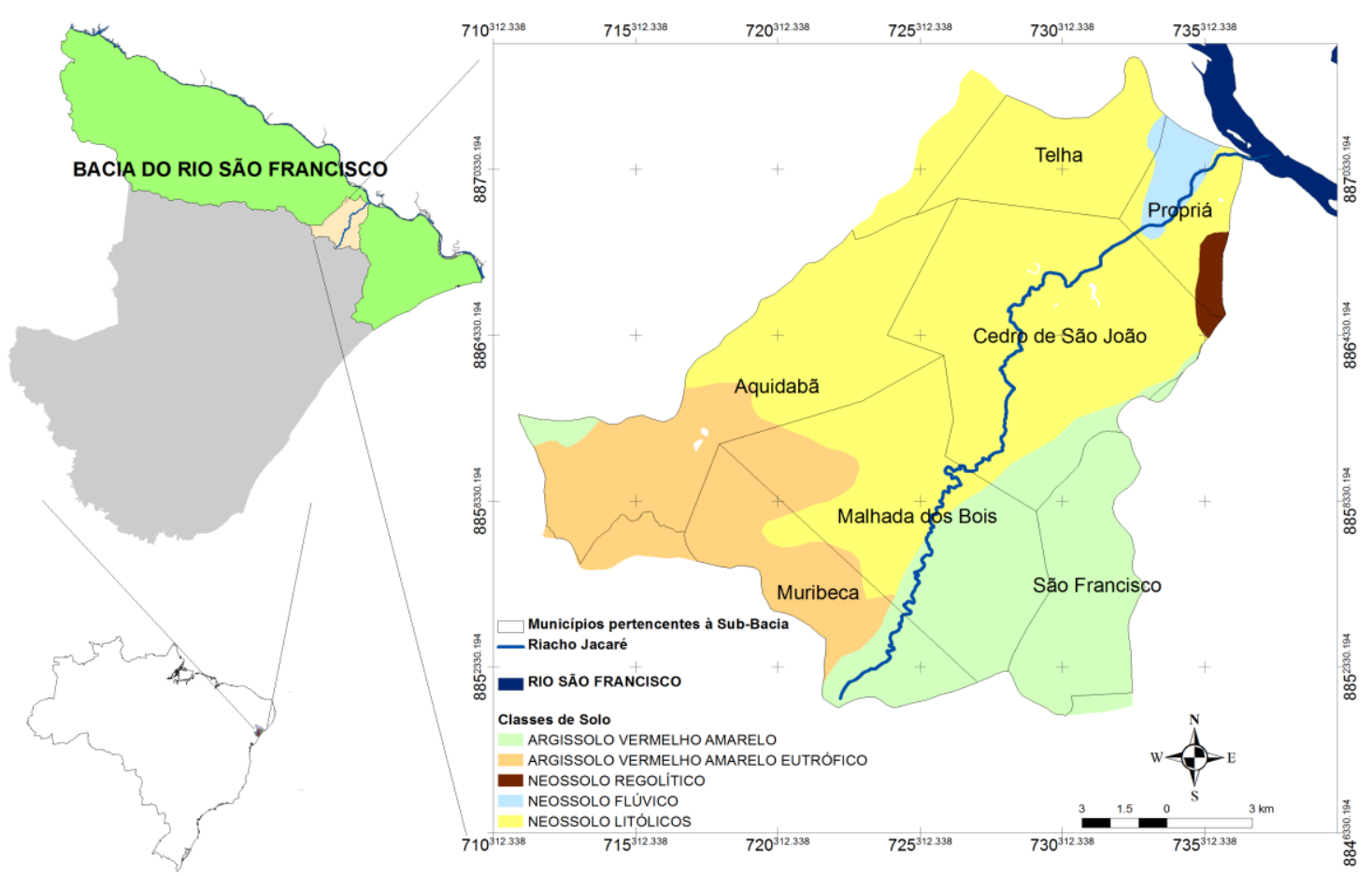

Figura 1. Localização da Sub-Bacia do Riacho Jacaré associado com as Classes de Solo presentes na localidade.

A declividade afeta o tempo de concentração da água na rede de drenagem da sub-bacia e constitui fator importante para a erodibilidade do solo.

De acordo com Sergipe (2004) o uso predominante do solo na sub-bacia é de pastagens (57,8\% da área total), seguido de matas secundárias $(31,4 \%)$, área cultivada $(8,2 \%)$, florestas $(2,2 \%)$, cidades $(0,3 \%)$ e solo exposto $(0,1 \%)$. $A$ principal exploração agrícola na sub-bacia é o cultivo do arroz, abrangendo uma área de 1934 ha, em que os principais municípios produtores são Propriá e Cedro de São João. As outras culturas produzidas na área são: milho, com 850 ha, e mandioca, com 200 ha (SRH, 2002). 


\section{Modelagem da produção de sedimento}

O modelo utilizado para determinar a produção de sedimento foi a equação universal de perda de solo modificada, MUSLE (Equação 1), por meio das análises de chuvas individuais considerando os processos hidrológicos ocorridos na bacia (WILLIAMS, 1975). A MUSLE dispensa a utilização de relações empíricas adicionais de aporte de sedimentos, e é aplicável a eventos isolados, tornando sua previsão mais precisa (WILLIAMS \& BERNDT, 1977).

$Y=89,6 \cdot(Q \cdot q p)^{0,56} \cdot K \cdot C \cdot L S \cdot P$

em que,

Y - aporte de sedimentos em um determinado exutório da bacia, após um evento de precipitação, ton $\mathrm{km}^{-2} \mathrm{ano}^{-1}$;

$\mathrm{Q}$ - volume de escoamento superficial total, $\mathrm{m}^{3}$;

$\mathrm{q}_{\mathrm{p}}$ - vazão pico do hidrograma resultante, $\mathrm{m}^{3} \mathrm{~s}^{-1}$;

$\mathrm{K}$ - erodibilidade do solo, (ton $\mathrm{h}$ ) (Mj $\mathrm{mm})^{-1}$;

$\mathrm{C}$ - fator de uso e manejo do solo;

LS - fator topográfico (declividade e comprimento de vertente);

$\mathrm{P}$ - fator associado à prática conservacionista;

Os valores de $Q$ e $q_{p}$ foram determinados com o modelo de análise de bacias complexas - ABC (OLIVEIRA et al., 2006). O modelo determina a distribuição temporal da chuva para diferentes durações (6, 12 e $24 \mathrm{~h}$ ) a partir da chuva acumulada no dia de acordo com a probabilidade de ocorrência da mesma ajustada pela distribuição de frequência Log Pearson Tipo III.

O volume do escoamento superficial foi obtido pelo método do Natural Resources Conservation Service - NRSC (HAWKINS at al., 2009) conforme as Equações 2 e 3 . $Q$ é obtido em $\mathrm{mm}$ e depois transformado para $\mathrm{m}^{3}$ multiplicando-se pela área da sub-bacia. A vazão de pico $\left(q_{p}\right)$ foi calculado pelo método do hidrograma unitário triangular sintético, conforme a Equação 4, e o tempo de pico $\left(T_{c}\right)$ pela Equação 5 (OLIVEIRA et al., 2006). Inicialmente foi determinado a capacidade máxima de armazenamento de água no solo (Sa) com base no parâmetro $\mathrm{CN}$ e, em seguida foi calculado o escoamento superficial direto. As classes de solos da sub-bacia foram convertidas para 
grupos hidrológicos do solo avaliando-se a classe de solo, a textura, o teor de argila, a profundidade e a permeabilidade de acordo com Sartori et al. (2005).

$$
\begin{gathered}
Q=\frac{(I-0,2 S a)^{2}}{I+0,8 S a} \\
S a=\frac{25400}{C N}-254 \\
q p=0,0021 \cdot Q \cdot \frac{A}{T p} \\
T c=1,18 \cdot\left(\frac{A^{0,41}}{S^{0,17}}\right)
\end{gathered}
$$

em que,

Q - volume de escoamento superficial direto de um evento de precipitação, $\mathrm{mm}$;

I - precipitação, mm;

$\mathrm{Sa}$ - retenção potencial máxima do solo a partir do início da precipitação, mm;

$\mathrm{CN}$ - número da curva que varia de 0 a 100 o qual depende da umidade antecedente do solo, do grupo hidrológico do solo e do uso e ocupação do solo;

$\mathrm{q}_{\mathrm{p}}$ - vazão de pico, $\mathrm{m}^{3} \mathrm{~s}^{-1}$;

A - área da bacia hidrográfica, $\mathrm{km}^{2}$;

$T_{c}$ - tempo de concentração, hora;

$\mathrm{S}$ - declividade, $\mathrm{m} \mathrm{km}^{-1}$.

A erodibilidade do solo (K) foi obtido de Silva et al. (2007) e os valores associados às classes de solo existentes na sub-bacia estudada foram: Neossolos Litólicos $(0,04)$, Neossolos Regolíticos $(0,041)$, Neossolos Flúvicos $(0,042)$, Argissolo Vermelho Amarelo $(0,04)$ e Argissolo Vermelho Amarelo Eutrófico $(0,04)$. 
O fator topográfico (LS) foi obtido com um aplicativo desenvolvido por Zhang et al. (2008) para o programa ArcGis denominado ArcMusle. O cálculo do fator LS foi realizado a partir do modelo digital de elevação da sub-bacia. Este aplicativo possibilitou a obtenção do fator LS de forma rápida e prática. O fator de uso e manejo do solo $(\mathrm{C})$ e o fator associado às práticas conservacionistas (P) foram obtidos de acordo com os dados da literatura, conforme a Tabelas 1.

Tabela 1. Valores utilizados para o fator de uso e manejo do solo (C) e para o fator associado às práticas conservacionistas $(P)$.

\begin{tabular}{|c|c|c|}
\hline \multirow[t]{2}{*}{ Cobertura do solo } & $\mathrm{C}$ & \multirow[t]{2}{*}{ Autores } \\
\hline & $\mathrm{P}$ & \\
\hline \multirow{2}{*}{ Mata secundaria } & 0,03241 & Silva (2007) \\
\hline & 0,5 & Pellizzetti et al. (2009) \\
\hline \multirow{2}{*}{ Solo exposto } & 1 & Farinasso et al. (2006) \\
\hline & 1 & Chaves et al. (2004) \\
\hline \multirow{2}{*}{ Cidades } & 0,001 & Farinasso et al. (2006) \\
\hline & 1 & Gonçalves \& Stape (2002) \\
\hline \multirow{2}{*}{$\begin{array}{l}\text { Área cultivada } \\
\text { (cultura anual) }\end{array}$} & 0,05 a 0,19 & Chaves \& Piau (2008) \\
\hline & 0,62 & Chaves et al. (2004) \\
\hline \multirow{2}{*}{$\begin{array}{c}\text { Área cultivada } \\
\text { (milho) }\end{array}$} & 0,025 a 0,156 & Machado et al. (2009) \\
\hline & 0,25 & Chaves et al. (2004) \\
\hline \multirow{2}{*}{ Floresta } & 0,012 a 0,032 & Gonçalves \& Stape (2002) \\
\hline & 0,001 & Gonçalves \& Stape (2002) \\
\hline \multirow[b]{2}{*}{ Pastagem } & 0,01 & Tomazoni et al. (2005) \\
\hline & 0,02 & Gonçalves \& Stape (2002) \\
\hline
\end{tabular}


O procedimento para a modelagem da produção de sedimento consistiu na determinação dos parâmetros necessários para utilização da MUSLE, em que alguns desses fatores foram obtidos com o auxilio do SIG (programa ArcGis), e os demais fatores foram obtidos com auxilio do programa ABC. No cálculo dos hidrogramas de escoamento superficial direto foram utilizados dados de precipitações diárias correspondente a uma série de 71 anos das estações pluviométricas de Propriá e Aquidabã (período de 1913 a 1984).

\section{Definição dos cenários de uso e ocupação do solo}

A fim de se aplicar a metodologia descrita com vista ao planejamento do uso e ocupação do solo, foram criados dois cenários para a sub-bacia do Riacho Jacaré tomando-se por base a condição atual. A análise consistiu em verificar a influência da vegetação sobre a produção de sedimentos. Foram propostos dois cenários contrastantes. O Cenário 1 , considerado ideal, previu um acréscimo de $77 \%$ das áreas de matas secundárias e uma redução de $42 \%$ das áreas de pastagem em relação a condição atual da sub-bacia. O Cenário 2 previu um acréscimo de $26 \%$ das áreas de pastagens e uma redução de $45 \%$ das áreas de matas secundárias em relação a condição atual da sub-bacia. $O$ Cenário 2 foi proposto para simular a situação em que ocorreriam as piores taxas de infiltração, maiores índices de escoamento superficial, uma vez que a cobertura vegetal foi significativamente reduzida. A distribuição das áreas segundo os grupos hidrológicos e os usos do solo na condição atual, para os dois cenários está apresentada na Tabela 2. A representação espacial dos Cenários 1 e 2 é apresentada na Figura 2 . 
Tabela 2. Distribuição de áreas segundo o grupo hidrológico e o uso e ocupação do solo na condição atual e nos Cenários 1 e 2 para a sub-bacia do Riacho Jacaré.

\begin{tabular}{ccccc}
\hline \multirow{2}{*}{$\begin{array}{c}\text { Grupo } \\
\text { hidrológico do } \\
\text { solo }\end{array}$} & Uso e ocupação do solo & \multicolumn{3}{c}{ Área $\left(\mathrm{km}^{2}\right)$} \\
\cline { 3 - 5 } & & Atual & Cenário 1 & Cenário 2 \\
& & & & \\
\hline \multirow{2}{*}{ Mata secundária } & 1,15 & 2,23 & 0,575 \\
& Pastagem & 2,15 & 1,08 & 5,9 \\
& Área cultivada & 6,34 & 6,34 & 3,17 \\
\hline \multirow{2}{*}{ C } & Mata secundária & 33,39 & 64,82 & 11,13 \\
& Solo exposto & 0,08 & 0,08 & 0,08 \\
& Cidades & 0,27 & 0,27 & 0,27 \\
& Área cultivada & 6,58 & 38,01 & 19,06 \\
& Pastagem & 94,29 & 31,43 & 105,42 \\
& Florestas & 2,69 & 2,69 & 1,34 \\
\hline \multirow{2}{*}{ D } & Mata secundária & 67,71 & 113,54 & 33,85 \\
& Solo exposto & 0,04 & 0,04 & 0,04 \\
& Cidades & 0,64 & 0,64 & 0,64 \\
& Área cultivada & 13,84 & 13,84 & 16,1 \\
& Pastagem & 91,66 & 45,83 & 125,52 \\
& Florestas & 4,52 & 4,52 & 2,26 \\
& & &
\end{tabular}




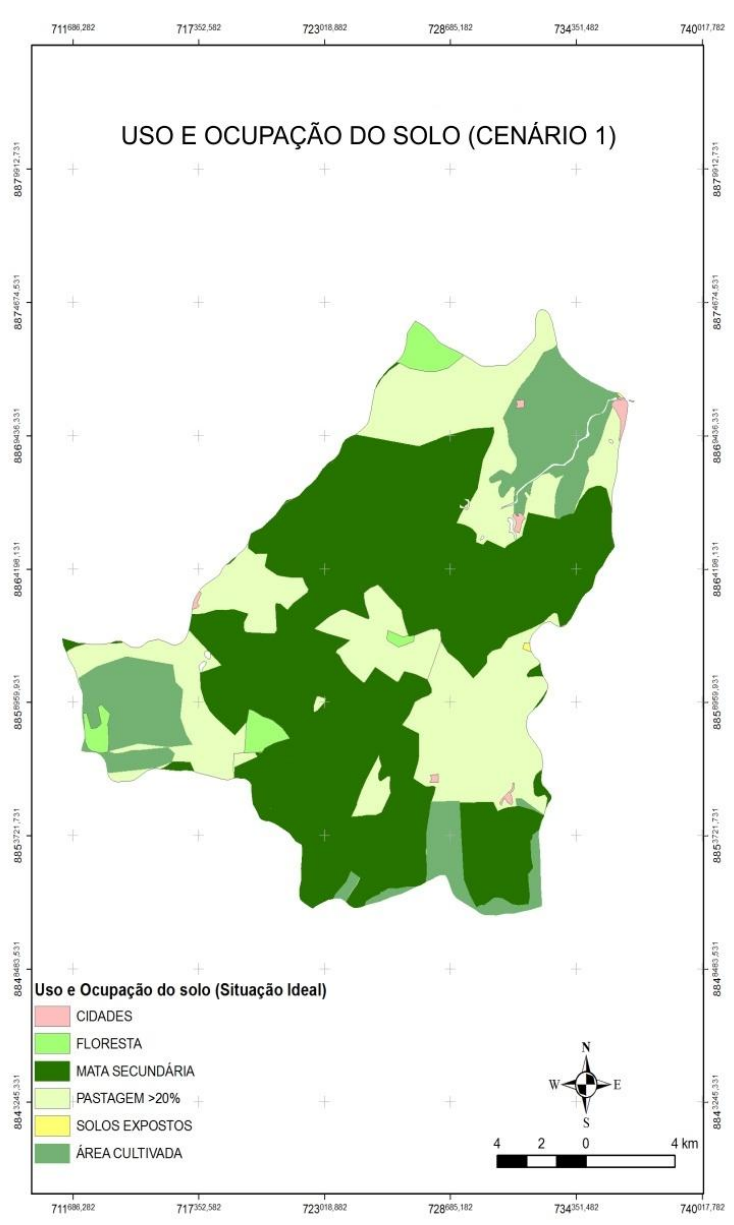

A

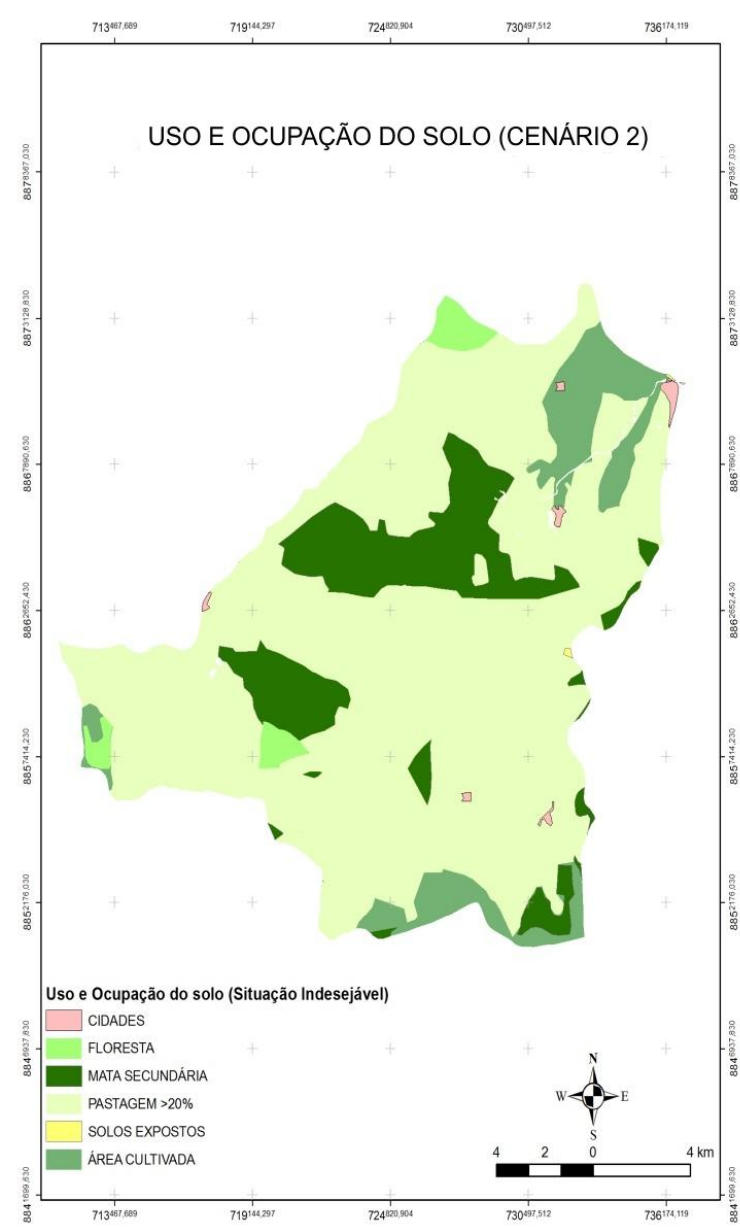

B

Figura 2. Mapa de uso e ocupação do solo da sub-bacia do Riacho Jacaré, para o cenário 1 - A (situação ideal) e o cenário 2 - B (situação indesejável).

\section{Resultados e Discussão}

A infiltração da água no solo e o coeficiente de escoamento superficial direto, para a situação atual e os cenários analisados, estão apresentados na Tabela 3. 
Tabela 3. Infiltração da água no solo e escoamento superficial direto para diferentes períodos de retorno (T) e duração da precipitação (D), para a situação atual e os Cenários 1 e 2, na sub-bacia do Riacho Jacaré.

\begin{tabular}{|c|c|c|c|c|c|c|c|}
\hline \multirow[t]{2}{*}{$\begin{array}{c}\mathrm{T} \\
\text { (anos) }\end{array}$} & \multirow[t]{2}{*}{$\begin{array}{l}D \\
(h)\end{array}$} & \multicolumn{3}{|c|}{$\begin{array}{l}\text { Infiltração } \\
\text { (mm) }\end{array}$} & \multicolumn{3}{|c|}{$\begin{array}{l}\text { Escoamento superficial direto } \\
\qquad(\mathrm{mm})\end{array}$} \\
\hline & & Atual & Cenário 1 & Cenário 2 & Atual & Cenário 1 & Cenário 2 \\
\hline \multirow{3}{*}{5} & 6 & 26,67 & 29,06 & 23,78 & 9,49 & 7,15 & 12,43 \\
\hline & 12 & 29,29 & 32,25 & 25,79 & 13,79 & 10,86 & 17,32 \\
\hline & 24 & 31,86 & 35,45 & 27,73 & 19,37 & 15,83 & 23,55 \\
\hline \multirow{3}{*}{25} & 6 & 32,34 & 36,04 & 28,08 & 20,62 & 16,92 & 24,88 \\
\hline & 12 & 34,85 & 39,23 & 29,93 & 28,22 & 23,84 & 33,14 \\
\hline & 24 & 37,24 & 42,32 & 31,66 & 37,80 & 32,72 & 43,38 \\
\hline \multirow{3}{*}{50} & 6 & 34,12 & 38,29 & 29,40 & 25,78 & 21,61 & 30,50 \\
\hline & 12 & 36,56 & 41,43 & 31,17 & 34,79 & 29,92 & 40,18 \\
\hline & 24 & 38,84 & 44,42 & 32,80 & 45,94 & 40,36 & 51,98 \\
\hline
\end{tabular}

À medida que se aumenta o período de retorno as precipitações médias aumentam e consequentemente ocorre uma elevação da infiltração da água no sol. Entretanto esse aumento foi sempre maior no Cenário 1 devido às melhores condições para a ocorrência deste processo ocasionadas pelo aumento da área de vegetação. Este comportamento fez com que 0 escoamento superficial direto fosse menor neste cenário, possibilitando uma maior infiltração. Os volumes dos hidrogramas e os picos das vazões foram menores para o Cenário 1, para todas as durações da precipitação, em todos os períodos de retorno (Tabela 4). 
Tabela 4. Vazão de pico e volume do hidrograma para diferentes períodos de retorno $(T)$ e duração da precipitação $(D)$, para a situação atual e os Cenários 1 e 2, na sub-bacia do Riacho Jacaré.

\begin{tabular}{|c|c|c|c|c|c|c|c|}
\hline \multirow[t]{2}{*}{$\begin{array}{c}\mathrm{T} \\
\text { (anos) }\end{array}$} & \multirow[t]{2}{*}{$\begin{array}{l}\text { D } \\
\text { (h) }\end{array}$} & \multicolumn{3}{|c|}{$\begin{array}{l}\text { Vazão de Pico } \\
\qquad\left(\mathrm{m}^{3} \mathrm{~s}^{-1}\right)\end{array}$} & \multicolumn{3}{|c|}{$\begin{array}{l}\text { Volume do hidrograma } \\
\qquad\left(10^{3} \mathrm{~m}^{3}\right)\end{array}$} \\
\hline & & Atual & Cenário 1 & $\begin{array}{c}\text { Cenário } \\
2\end{array}$ & Atual & $\begin{array}{c}\text { Cenário } \\
1\end{array}$ & Cenário 2 \\
\hline \multirow{3}{*}{5} & 6 & 106,7 & 80,12 & 139,82 & 3,121 & 2,351 & 4,087 \\
\hline & 12 & 135,77 & 105,57 & 172,74 & 4,536 & 3,572 & 5,696 \\
\hline & 24 & 168,97 & 134,43 & 210,03 & 6,373 & 5,208 & 7,746 \\
\hline \multirow{3}{*}{25} & 6 & 231,86 & 190,44 & 279,13 & 6,782 & 5,566 & 8,183 \\
\hline & 12 & 282,89 & 237,04 & 334,23 & 9,283 & 7,843 & 10,902 \\
\hline & 24 & 339,96 & 290,20 & 394,07 & 12,435 & 10,764 & 14,271 \\
\hline \multirow{3}{*}{50} & 6 & 289,63 & 243,13 & 341,78 & 8,481 & 7,108 & 10,035 \\
\hline & 12 & 350,03 & 299,02 & 405,99 & 11,445 & 9,842 & 13,218 \\
\hline & 24 & 415,75 & 361,33 & 474,26 & 15,112 & 13,277 & 17,100 \\
\hline
\end{tabular}

Esses resultados demonstram que em áreas onde ocorre a maior presença de vegetação esses índices são menores devido à maior capacidade de infiltração.

A produção de sedimentos obtidos para todas duas situações simuladas (Tabela 5) mostram que, em todos os casos, o Cenário 1 produziu uma quantidade muito inferior de sedimentos em comparação com a situação atual e o Cenário 2. 
Tabela 5. Produção de sedimentos para diferentes períodos de retorno (T) e duração da precipitação (D), para a situação atual e os Cenários 1 e 2, na subbacia do Riacho Jacaré.

\begin{tabular}{ccccc}
\hline T (anos) & $\mathrm{D}(\mathrm{h})$ & \multicolumn{3}{c}{ Produção de sedimentos (ton $\mathrm{km}^{-2} \mathrm{ano}^{-1}$ ) } \\
\cline { 3 - 5 } & & Atual & Cenário 1 & Cenário 2 \\
\hline \multirow{2}{*}{5} & 6 & 6,437 & 4,678 & 8,710 \\
& 12 & 9,082 & 6,901 & 11,808 \\
& 24 & 12,420 & 9,759 & 15,649 \\
\hline \multirow{2}{*}{25} & 6 & 15,35 & 12,310 & 18,924 \\
& 12 & 20,46 & 16,863 & 24,580 \\
& 24 & 26,71 & 22,550 & 31,343 \\
\hline \multirow{2}{*}{50} & 6 & 19,70 & 16,187 & 23,760 \\
& 12 & 25,92 & 21,809 & 30,531 \\
& 24 & 33,34 & 28,674 & 38,474 \\
\hline
\end{tabular}

Este fato deve-se a uma maior quantidade de vegetação encontrada no Cenário 1. A produção de sedimento na sub-bacia do Riacho Jacaré pode ser considerada baixa levando-se em conta os níveis alcançados no Brasil. Carvalho (2008) apresentou valores de 5 a 70 ton $\mathrm{km}^{-2} \mathrm{ha}^{-1}$ para esta categoria. Mesmo para a condição mais crítica de uso e ocupação do solo analisada (Cenário $2, T=50$ anos e $D=24 \mathrm{~h}$ ) a produção de sedimento na sub-bacia alcança $55 \%$ do limite superior da classe atribuída como baixa.

O aumento da área de mata secundária no solo das classes Argissolo Vermelho Amarelo e Argissolo Vermelho Amarelo Eutrófico (Cenário 1) possibilitou uma maior infiltração e, consequentemente menores volumes de escoamento superficial direto, proporcionando um menor potencial de erosão. No Cenário 2 as áreas que apresentavam mata secundária foram retiradas predispondo ainda mais as mesmas aos processos erosivos, visto que a proteção e o aumento das taxas de infiltração da água no solo proporcionados pelas pastagens, não apresentam bons resultados como as matas secundárias. 
Os resultados obtidos neste trabalho mostraram a importância da cobertura de mata secundária em áreas que apresentam alta suscetibilidade ao processo erosivo devido as suas características físicas e a alta declividade. Outros trabalhos avaliaram outros tipos de cobertura vegetal e mostraram resultados semelhantes. Carvalho et al. (2009) constataram uma redução do escoamento superficial e a perda de água de 33 e $26,5 \%$ em solo com Crotolária em relação ao solo exposto, evidenciando a importância da cobertura vegetal para reduzir a produção de sedimento. Panachuki et al. (2006) verificaram maiores valores médios de escoamento superficial e menores perdas de solo no sistema de pastagem em relação ao sistema de cultivo em plantio direto com resto vegetal de soja. Embora a pastagem proporcione uma melhor agregação do solo devido à ação do sistema radicular e ao maior teor de matéria orgânica, o pisoteio animal pode compactar a camada superficial do solo facilitando 0 escoamento.

Em ambos os cenários estudados previram aumentos das áreas cultivadas em relação à condição atual, 117\% para o Cenário 1 e 43\% para o Cenário 2. Embora a área cultivada tenha sido maior no Cenário 1, a sua ocorrência associada a uma maior área de mata secundária contribuiu para reduzir o escoamento superficial direto. Nas áreas cultivas a cobertura do solo também assume grande importância na característica do escoamento. Silva et al. (2005 b) verificaram uma diminuição da perda de água e de solo com o aumento da percentagem de cobertura do solo chegando respectivamente a 83,6 e $87,1 \%$ quando a cobertura aumentou de 0 para $80 \%$. Silva et al. (2005 a) verificaram o sistema de plantio direto proporcionam maior acúmulo de cobertura vegetal na superfície do solo promovendo a redução da velocidade do escoamento superficial devido ao aumento da rugosidade hidráulica e uma menor perda de solo.

Os Neossolos Litólicos e os Regolíticos apresentam pouca profundidade e geralmente são encontrados em regiões com altas declividades. Na maioria dos casos são inadequados para o plantio de espécies agrícolas. Sua utilização de acordo com Oliveira (2005) esta relacionada como áreas de reserva natural. Para o Cenário 1 é recomendado que as áreas que 
apresentavam pastagens nessas classes de solo sejam substituídas por plantas nativas ou árvores que apresentem um sistema radicular não muito profundo e resistente, visto as propriedades físicas encontradas nessa classe de solo, a fim de proporcionar uma maior taxa de infiltração.

Outros cenários de uso e ocupação do solo poderiam ser simulados com o intuito de quantificar o impacto sobre a produção de sedimento de acordo com as características hidrológicas e pluviométricas da bacia. A metodologia que combina o uso de um modelo hidrológico, da MUSLE e de um SIG, permitiu uma análise rápida e prática de quaisquer situações facilitando o planejamento agrícola e ambiental. Fohrer et al. (2001) e Machado et al. (2003) concordam dizendo que os modelos servem para auxiliar numa melhor compreensão sobre os processos que ocorrem no sistema de forma econômica, rápida e prática. Conforme comentado por Farinasso et al. (2006) e Candido et al. (2010), o uso do SIG e contribui como ferramenta auxiliar para preparação dos dados bem como para a visualização dos resultados facilitando a análise das condições de manejo. Podem ser citados como exemplos o aplicativo utilizado para o cálculo do fator de declividade do solo (Zhang et al., 2009) que facilitou o processo de cálculo, e o SIG utilizado para a preparação dos dados para o cálculo do escoamento superficial. Estas aplicações têm se constituído numa importante ferramenta para o planejamento e para o manejo sustentável das bacias hidrográficas.

\section{Conclusões}

As simulações mostraram o efeito benéfico que a mata secundária exerce no controle da produção de sedimentos em bacias hidrográficas. $O$ aumento da vegetação proporcionou melhores efeitos para diminuir as perdas de solo e 0 escoamento superficial direto na sub-bacia do Riacho Jacaré. $O$ aumento da duração da precipitação e do período de retorno aumenta o escoamento superficial direto em termos de volume do hidrograma e da vazão de pico que por sua vez provocam aumento da produção de sedimento. A produção de sedimento na sub-bacia foi considerada baixa mesmo na condição em que 
14,7\% da área da bacia poderiam ser ocupadas com mata secundária e florestas, e 72,8\% com pastagem.

A metodologia utilizada mostrou-se adequada para o propósito de planejamento do uso e ocupação do solo em bacias hidrográficas visando minimizar a produção de sedimentos, podendo também ser utilizada para 0 planejamento agrícola e ambiental. Diferentes situações de manejo da bacia poderão ser simuladas para verificar o efeito dos eventos hidrológicos sobre a produção de sedimentos.

\section{Referências Bibliográficas}

AGUIAR NETTO, A. de O.; SANTOS, D.; MOREIRA, F. D. Caminhos da Gestão de Recursos Hídricos: $O$ caso da Sub-Bacia Hidrográfica do Riacho Jacaré, Baixo São Francisco Sergipano. Revista Irriga, v. 13, n. 1, p. 12-25, 2008.

CANDIDO, H.G.; GALBIATTI, J.A.; PISSARRA, T.C.T.; MARTINS FILHO, M.V. Degradação ambiental da bacia hidrográfica do Rio Uberaba: uma abordagem metodológica. Engenharia Agrícola, v.30, n.1, p.179-92, 2010.

CARVALHO, N.O. Hidrossedimentologia prática. CPRM, 599p, 2008.

CARVALHO, D.F.; CRUZ, E.S.; PINTO, M.F.; SILVA, L.D.B.; GUERRA, J.G.M. Características da chuva e perdas por erosão sob diferentes práticas de manejo do solo. Revista Brasileira de Engenharia Agrícola e Ambiental, v.13, n.1, p.3-9, 2009.

CHAVES, H.M.L.; BRAGA, B.; DOMINGUES, A.F.; SANTOS, D.G. dos. Quantificação dos benefícios e compensações do "Programa do Produtor de água" (ANA): I Teoria. Revista Brasileira de Recursos Hídricos, v.9, p.5-14, 2004.

CHAVES, H.M.L. \& PIAU, L.P. Efeito da variabilidade da precipitação pluvial e do uso e manejo do solo sobre o escoamento superficial e o aporte de sedimento de uma bacia hidrográfica do Sistrito Federal. Revista Brasileira de Ciência do Solo, v.32, p.333-343, 2008.

FARINASSO, M.; CARVALHO JÚNIO, O.A.; GUIMARÃES, R.F.; GOMES, R.A.T.; RAMOS, V.M. Avaliação qualitativa do potencial de erosão laminar em grandes áreas por meio da Eups utilizando novas metodologias em sig para os cálculos dos seus fatores na região do Alto Parnaíba - PI - MA. Revista Brasileira de Geomorfologia, ano 7, p.73-85, 2006. 
GONÇALVES, J.L.M. \& STAPE, J.L. Conservação e cultivo de solos para plantações florestais. Piracicaba: IPEF, 498p, 2002.

HAWKINS, R.H; WARD, T.J.; WOODWARD, D.E.; VAN MULLEN, J.A. Curve number hydrology: state of the practice. Reston: ASCE, 106 p, 2009.

MACHADO, M.L.; ALVES, J.S.; GOMES, I.; VIEIRA, E.M.V.; SIMÃO, M.L.R.; NAIME, U.J. Levantamento sistemático dos fatores da Equação Universal de Perdas de Solos (USLE) para o delineamento de áreas com potencial erosivo da bacia PN1 - IGAM, Minas Gerais (resultados parciais). In: SIMPÓSIO BRASILEIRO DE SENSORIAMENTO REMOTO, 14., 2009, Natal. Resumo Expandido..., INPE, 2009, p. 7733-7739.

MACHADO, R.E.; VETTORAZZI, C.A.; XAVIER, A.C. Simulação de cenários alternativos de uso da terra em uma microbacia utilizando técnicas de modelagem e geoprocessamento. Revista Brasileira de Ciência do Solo, v.27, p. 727-733, 2003.

OLIVEIRA, J. B. de. Pedologia Aplicada. Piracicaba: FEALQ, 574 p, 2005.

OLIVEIRA, C.P.M.; MELLO JÚNIOR, A.V.; MARCELLINI, S.S.; PORTO, R.L.L. Sistema de Apoio para Determinação de Vazões de Projeto em Bacias Complexas com Base em Precipitações Máximas. In: SIMPÓSIO DE RECURSOS HÍDRICOS DO SUL-SUDESTE, 1., 2006, Curitiba. Resumo Expandido... Porto Alegre: ABRH, 2006. 1 CD-ROM.

PANACHUKI, E.; ALVES SOBRINHO, T.; VITORINO, A.C.T.; CARVALHO, D.F.; URCHEI, M.A. Parâmetros físicos do solo e erosão hídrica sob chuva simulada, em área de integração agricultura-pecuária. Revista Brasileira de Engenharia Agrícola e Ambiental, v.10, n.2, p.261-8, 2006.

PELLIZZETTI, M.A.; VIBRANS, A.C.; FRANK, B. Estimativa do percentual de abatimento de erosão para as condições da bacia do Itajaí. In: SEMINÁRIO DE RECURSOS HÍDRICOS DA BACIA HIDROGRÁFICA DO PARAÍBA DO SUL, 2., Taubaté. Resumo Expandido... Taubaté: IPABHi, 2009. p. 341-350.

SARTORI, A.; LOMBARDI NETO, F.; GONOVEZ, A.M. Classificação hidrológica de solos brasileiros para a estimativa da chuva excedente com o método do serviço de conservação do solo dos Estados Unidos Parte 1: Classificação. Revista Brasileira de Recursos Hídricos, Porto Alegre, v. 10, n.4, p. 5-18, 2005.

SERGIPE (Estado). Superintendência de Recursos Hídricos. Atlas Digital sobre os Recursos Hídricos de Sergipe. ARACAJU: SEPLANTEC-SRH, CD-ROM, 2004.

SILVA, A.M.; SCHULZ, H.E.; CAMARGO, P.B. Erosão e hidrossedimentologia em bacias hidrográficas. São Carlos: Rima, 153p, 2007.

SILVA, C.G.; SOBRINHO, T.A.; VITORINO, A.C.T.; CARVALHO, D.F. Atributos físicos, químicos e erosão entressulcos sob chuva simulada, em sistemas de 
plantio direto e convencional. Engenharia Agrícola, v.25, n.1, p.144-153, 2005 a.

SILVA, D.D.; PRUSKI, F.F.; SCHAEFER, C.E.G.R.; AMORIM, R.S.S.; PAIVA, K.W.N. Efeito da cobertura nas perdas de solo em um Argissolo VermelhoAmarelo utilizando simulador de chuva. Engenharia Agrícola, v.25, n.2, p.409419, 2005 b.

SILVA, L.F. da. A construção de um índice de sustentabilidade ambiental agrícola (ISA): uma proposta Metodológica. Campinas: Unicamp, 232p, 2007,

SRH. SUPERINTENDÊNCIA DE RECURSOS HÍDRICOS. Diagnóstico dos municípios de Propriá e Cedro de São João. Aracaju, 2002.

TOMAZONI, J.C.; MANTOVANI, L.E.; BITTENCOURT, A.V.L.; ROSA FILHO, E. F. A sistematização dos fatores da Eups em sig para quantificação da erosão laminar na bacia do rio Anta Gorda (PR). Estudos Geográficos, Rio Claro, v.3, p.1-21, 2005.

VESTENA, L.R. Análise da dinâmica hidrossedimentológica em uma bacia hidrográfica no sul do Brasil. Sociedade \& Natureza, v.21, n.3, p.413-24, 2009.

ZHANG, Y.; DEGROOTE, J.; WOLTER, C.; SUGUMARAN, R. Integration of Modified Universal Soil Loss Equation (MUSLE) into a gis framework to assess soil erosion risk. Land Degradation \& Development, v.20, p.84-91, 2009.

WILLIAMS, J.R. HYMO flood routing. Journal of Hydrology, v.26, p.17-27, 1975.

WILLIAMS, J.R. \& BERNDT, H.D. Sediment Yield Prediction Based on Watershed Hydrology. Transaction of the American Society of Agricultural Engineers, v.20, p.1100-1104, 1977.

WISCHMEIER, W.H. \& SMITH, D.D. Predicting rainfall erosion losses - guide to conservation planning. Washington: ESDA, 58p, 1978. 